\title{
Imperialismo y globalización \\ (A propósito del libro de Atilio Boron: Imperio \& imperialismo)
}

\author{
Imperialism and globalization \\ (About the book by Atilio Boron: Empire \& imperialism)
}

${ }^{1}$ José Virgilio Mendo

\section{RESUMEN}

En el presente artículo se propone abordar una observación concreta sobre lo que, personalmente, constituye un punto de partida en el libro de Atilio Boron, Imperio \& imperialismo (Una lectura crítica de Michel Hardt y Antonio Negri), la dilucidación de los rasgos constitutivos del imperialismo en el momento actual. Por ello, será necesario hacer precisiones sobre la naturaleza del imperialista en cuanto a ser la última fase del capitalismo (Lenin) y a su configuración en neoimperialismo o de globalización neoliberal. No se trata de observar dicha configuración a nivel gradual o fenoménico, como lo sostiene Atilio Boron, sino de la trasformación del conocimiento bajo su forma mercancía. Por ello, sostengo que la globalización neoliberal corresponde a la última etapa de reorganización de las relaciones de producción capitalistas en el imperialismo.

Palabras clave: Conocimiento, globalización, imperialismo, mercancía.

ABSTRACT

In this article we propose to address a concrete observation to what, personally, constitutes a starting point in Atilio Boron's book, Empire \& Imperialism (A critical reading by Michel Hardt and Antonio Negri), the elucidation of the constitutive features of imperialism at the present time. Therefore, it will be necessary to make precisions on the nature of imperialism as being the last phase of capitalism (Lenin) and its configuration in neo-imperialism or neoliberal globalization. It is not a matter of observing such configuration at a gradual or phenomenal level, as Atilio Boron argues, but of the transformation of knowledge under its commodity form. Therefore, I maintain that neoliberal globalization corresponds to the last stage of reorganization of the capitalist relations of production in imperialism.

Key words: Knowledge, globalization, imperialism, merchandise.

\section{INTRODUCCIÓN}

No es mi intención iniciar una crítica al importante libro de Atilio Boron: Imperio \& imperialismo (Una lectura crítica de Michel Hardt y Antonio Negri), sino aportar con algo que me parece necesario para esclarecer el entendimiento de lo que está ocurriendo actualmente con los estudios sobre globalización. Me refiero a que en ninguna parte del libro en referencia se hace una distinción clara y conceptual entre el imperialismo tradicional, el de "hace treinta años" como afirma Boron, y el de ahora. Me parece muy correcta la puntualización que hace el autor cuando afirma que la globalización neoliberal actual no es sino una fase del imperialismo -opinión que, por otra parte, la comparte con otros intelectuales, por ejemplo James Petras -, fase que conserva todos los rasgos anteriores o iniciales del imperialismo tal

${ }^{1}$ Filósofo, sociólogo y educador. Docente de la Escuela de Postgrado de la UNMSM. Director del Departamento de Investigaciones del ISP San Marcos. E-mail: jvmendo@gmail.com

Presentado: 27/02/2020, Aprobado: 24/06/2020 
como Lenin lo señalara en Imperialismo, última fase del capitalismo, pero al mismo tiempo, este neoimperialismo o globalización tiene rasgos distintivos que lo hacen específico. Entonces, si esto es así, se presenta la necesidad de saber en qué consiste esa diferencia; lo cual tiene una importancia no solo teórica, sino eminentemente práctica: la comprensión de los rasgos del imperialismo actual dan paso a formas de lucha política a través de organizaciones populares y democráticas, del contenido programático y de la práctica de las estrategias apropiadas para establecer el nuevo orden social. Por otra parte, que el imperialismo actual tenga sus rasgos distintivos no significa, repito, que este se haya modificado a tal grado que haya dejado de existir, tal como Hardt y Negri, según Boron, lo sostienen, sino que solo ha cambiado de fisonomía, pero no de esencia. La globalización neoliberal corresponde a la última etapa de reorganización de las relaciones de producción capitalistas en el imperialismo.

\section{Algunas precisiones en torno al imperialismo}

El análisis económico, que lo anterior implica, solo quiere significar que la necesidad de ir más allá de la interrelación de lo político con lo económico y cultural, esto es, la necesidad de mirar hacia lo global $\mathrm{y}$ profundo de dichos procesos tiene que comenzar con un análisis económico de lo que está sucediendo en esta fase última del imperialismo que muchos despreocupadamente o estereotipadamente llaman globalización. Como sabemos, el imperialismo es la etapa en la que el capital financiero, debido a diferentes causas y procesos de orden histórico, económico, político, cultural y financiero, toma el control de todos los procesos productivos, de tal manera que estos no pueden movilizarse ni realizarse en adelante sin el financiamiento correspondiente. Debido a este hecho, el capital financiero toma el control del capital industrial para obtener las más altas tasas de rentabilidad y expandirse por todo el mundo a través de transnacionales a las cuales financia. El capital industrial se convierte en dependiente del financiero a la vez que este último se convierte en la principal fuente de acumulación.

Esto no significa que el sector industrial haya desaparecido o tienda a desaparecer, tal como Peter Drucker lo señala reiteradamente (La sociedad postcapitalista [1994]). Por el contrario, se puede afirmar que en esta fase del imperialismo llamada globalización, nunca antes como ahora, la industrialización es más intensa y extensa. Téngase en cuenta que estamos hablando desde la lógica de las transnacionales. En realidad, la industrialización es un proceso contradictorio, significa el crecimiento de la industrialización en aquellos tipos específicos de actividad productiva y regiones que son de interés de las empresas metropolitanas de carácter internacional, y, al mismo tiempo, la desindustrialización y la no industrialización de los países de la periferia, en aspectos en los que no interesa a ese capital financiero internacional.

Apuntemos también que este proceso de industrialización se basa en que, nunca como en la presente época, la tasa de plusvalía de las empresas correspondientes al sector industrial ha llegado a tan alto nivel, tal como lo ilustra el caso de todos los países asiáticos de reciente industrialización. Se puede afirmar que el "milagro" de Corea del Sur, Tailandia, Formosa, Indonesia y otros países asiáticos, representa el esfuerzo de los capitales principalmente norteamericanos para huir de la tasa descendente de ganancia, elevando la productividad y (al mismo tiempo) la tasa de plusvalía. Elevación para la cual, las empresas recurren a los más bajos salarios dentro de la economía global.

El imperialismo es la fase del capitalismo en la que el dinero se ha convertido en un tipo específico de mercancía. De tal manera que el capital-dinero se invierte en dinero (préstamos, colocaciones, etc.) para producir más dinero (tasas de interés, etc.), sin tener que pasar-directamente por lo menos- por los canales de la industrialización. Dicho de una manera más específica, el dinero, a su primera forma como equivalente general del valor, le sucede ahora una transmutación y se convierte en mercancía de sí misma, en mercancía de su propia mercancía porque su realización se desenvuelve dentro del ámbito del propio dinero. Aun cuando el capital industrial está fuertemente articulado al financiero, se presenta una relativa autonomía entre ambas esferas. Autonomía que posibilita, en determinadas condiciones históricas, que el capital financiero, como lo hemos señalado antes, someta al industrial.

En las fases anteriores al imperialismo, es decir, en la época del capitalismo comercial y en las primeras fases de la acumulación del capital industrial que corresponde a la etapa del capitalismo ascensional en los países que hoy son centrales, el capital se acumulaba, formaba y se invertía dentro de las fronteras nacionales, fortaleciendo la burguesía nacional y dando paso a lo que se denomina Estado- 
Nación en cada país, como sucedió hasta finales del siglo XIX. En cambio, en la época del imperialismo, el capital rebasa las fronteras nacionales y se expande a otras regiones, de las cuales forma verdaderos imperios cuyos centros son las fronteras nacionales o el Estado-Nación de cada país hegemónico.

Este sentido, la expansión de la acumulación beneficia al Estado-Nación imperialista, estableciéndose mecanismos de explotación de unos países sobre otros y dando lugar a una nueva división internacional del trabajo.

Nunca dejará de ser fundamental comprender este proceso de expansión del capital financiero e industrial como un proceso sumamente contradictorio, que implica el hambre, la pobreza y la desesperación de grandes masas de la población en cada país, debido a la falta de empleos y a la ausencia de políticas nacionales de desarrollo interno que pongan énfasis en la industrialización y en el desarrollo del agro o de la agroindustria. También el desarrollo de la biotecnología, que, según se dice, en el futuro estará llamada a adquirir enorme importancia, rama en la cual nuestro país es privilegiado respecto de todos los demás, constituyendo una de sus principales "ventajas comparativas".

Es decir, si bien en la globalización neoliberal se ha producido una denominada "desterritorialización" de las actividades productivas controladas por las transnacionales, la rentabilidad de estas actividades, constituyentes en gran parte del capital financiero, la acumulación se produce para los países hegemónicos o Estados-Nación imperialistas en los cuales se centra el poder económico-financiero de las grandes empresas transnacionales. Acumulación de unos, polarización de la riqueza en manos cada vez más reducidas, este proceso implica como contrapartida, la explotación sin nombre de los países periféricos y su empobrecimiento, es decir, la constitución de las "venas abiertas de América Latina" (Eduardo Galeano).

En cuanto al Estado-Nación, los tiempos han cambiado, es cierto, y ya no podemos hablar de Estado-Nación para cualquier país al estilo de los siglos XVIII y XIX. Es decir, ya no se presentará más en el escenario histórico mundial el surgimiento de nuevos Estados-Nación, tal como estos estuvieron definidos por la soberanía y la (casi) autarquía dada por el desarrollo de una burguesía nacional en lucha a muerte - como lo afirma Antonio Negri -, contra el enemigo fundamental de esta burguesía: la "clase obrera", "los campesinos" y "todos aquellos que acumulan para el capital" (Entrevista por el diario $L a$ Jornada, julio 2001. Hemos escrito "acumulan" en presente y no "acumulaban" en pasado, como figura en el original)

Pero, junto con Atilio Boron, no podemos estar de acuerdo $-\mathrm{y}$ esto es fundamental - con que la configuración Estado-Nación se encuentre en pleno e irreversible proceso de desaparición a causa de la globalización, cuando justamente - y en esto nuevamente estamos de acuerdo con Boron - a causa precisamente de esta globalización se experimenta como nunca antes un fortalecimiento extraordinario del Estado-Nación, pero limitado esta vez solo a los países hegemónicos que en el pasado lograron constituirse como Estados-Nación.

Dicho de otra manera, en la actualidad, se presentan dos tipos de Estado:

a) Lo que podría denominarse verdaderos Estados-Nación que son únicamente los países imperialistas.

b) El resto de los Estados, esparcidos por todo el mundo, pálidos reflejos de un Estado con autonomía y soberanía, incapaces de establecer políticas democráticas de desarrollo nacional en su país, instrumentos de las colocaciones directas de las transnacionales y de sus organismos de fachada BM, FMI, OMC y otros.

Claro que la llamada "teoría política" de los intelectuales orgánicos del imperialismo pasa por alto estas realidades y hablan sin ningún escrúpulo del "cambio del rol del Estado en la sociedad moderna", de las nuevas formas que adquiere el "Estado moderno", de la periclitación sin remedio de las funciones tradicionales del Estado, sin ver el elefante que se interpone ante sus ojos. Como lo sugerimos en líneas arriba, no estamos defendiendo, cual ilusos, la configuración del Estado de siglos pasados. En la actualidad, el Estado ha cambiado en sus funciones debido principalmente al cambio del escenario económico y sociocultural actual, en el que las teorías fundamentalistas neoliberales tienen su papel, teorías neoliberales que proclaman la "libertad irrestricta" de los ciudadanos también "modernos "o, mejor, "postmodernos". En la base de la "teoría de la moderna ciudadanía" se encuentra el supuesto de que los "individuos" son precisamente eso, individuos absolutamente 
desprovistos de vínculos sociales, pero individuos de cuya libertad y toma de conciencia, debido principalmente a la educación, se desprenden en un segundo momento, derechos y obligaciones que se manifiestan a su vez en la constitución de sociedades "libres y democráticas" concretas.

Lo que criticamos en esas formulaciones "postmodernas" es que no ven, no pueden ver, que no existe un solo tipo de Estado y que hablar en general de las características del "Estado Moderno" es en realidad hablar, por una parte, del Estado de los países hoy hegemónicos en contra de la realidad que se presenta en los países de la periferia o predicar, por otra parte, una entelequia abstracta hecha para el consumo concreto de esos países periféricos o explotados.

En el hemisferio sur, en los países llamados del Tercer Mundo o como más propiamente Boron o Samir Amin los denominan "capitalismos periféricos", la situación es exactamente contraria a la de los países centrales. El debilitamiento del Estado y no solo de este, sino de la sociedad y de la cultura entera, ha llegado a límites altamente inquietantes, en las que predomina el discurso neoliberal y sin freno en todos los aspectos $\mathrm{y}$ dimensiones de la vida. Las páginas dedicadas por Boron al análisis de casos concretos (p.e. págs. 93 y sgtes.) son bastante elocuentes. El doble discurso es el que campea, proteccionismo para mí, pero liberalismo sin límites para ti. La principal característica de la ideología neoliberal es que es un discurso abstracto-especulativo; y, por tal, entendemos su unilateralidad, su ausencia de la visión global o de la totalidad, su falta de análisis histórico-dialéctico y su esfuerzo siempre fracasado (pero válido para los intonsos) de absolutizar para toda la sociedad, lo que es válido solamente para una parte de ella, aquella que conviene a los intereses de las transnacionales. Por eso, el discurso neoliberal aparece como general, que, como Jano, esconde tras esa generalidad el doble discurso, sus dos caras, su doble faz.

\section{El conocimiento como mercancía}

Llegados a este punto de la exposición, es menester hacer un intento de respuesta a la pregunta formulada al comienzo: ¿La distinción entre el imperialismo actual llamado globalización neoliberal y el anterior es solamente de grado? Así parecen sostenerlo innumerables autores, entre ellos el mismo Boron.
Pero esta posición no es, de ninguna manera, ni satisfactoria ni explicativa desde el punto de vista del análisis teórico. Esta nueva etapa del imperialismo no es cuestión meramente cuantitativa ni mucho menos acumulativa. Lo que señala Boron: "La concentración del capital, el abrumador predominio de los monopolios, el acrecentado papel del capital financiero, la exportación de capitales y el reparto del mundo en distintas "esferas de influencia", la "aceleración del proceso de mundialización acontecida en el último cuarto de siglo" que no hizo sino "potenciar extraordinariamente las asimetrías estructurales que definen la inserción de los distintos países" (pág.11) en las estructuras imperialistas, todo esto, además de pasar por encima y no mencionar otros aspectos decisivos como el nuevo carácter de la industrialización actual o el papel de las nuevas tecnologías de informacióncomunicación (NTICs), todo eso decía, son solamente descripciones que no alcanzan a explicar la naturaleza específica de la presente etapa del imperialismo. Llama sumamente la atención que Borón no dedique ni una sola línea, en el texto que comentamos, al papel que cumplen los modernos m e dios t e c no-ele ctrón i cos d e comunicación/información en la configuración de las actuales sociedades.

Sostenemos que esa especificidad se define por la siguiente tesis: la globalización, entendida como una nueva etapa de reorganización de las relaciones de producción capitalistas en el imperialismo, se produce cuando el conocimiento se transforma en la forma mercancía y, al hacerlo, se universaliza y se vuelve obligatoria a nivel de todo el conjunto social. Desde este momento, ninguna actividad productiva alcanzará el nivel de productividad media o standard, necesaria para competir en el fiero mercado nacional e internacional, si es que no incorpora a sus procesos de producción el conocimiento bajo la forma mercancía. Aquí haré algunas observaciones.

$1^{\circ}$ En verdad, no se trata del conocimiento, sino del conocimiento bajo su forma mercancía: la información. Sostenemos también que tan pronto el conocimiento se inserta en una "racionalidad instrumental", deja de ser conocimiento y pasa a ser información. Se dice que la información, por lo menos en el significado que nos interesa, es el conocimiento puesto "al servicio de" y, en este sentido, es sinónimo de poder y manipulación. Aquí adquiere pertinencia la observación de Francis 
Bacon, allá en los comienzos del siglo XVII: "saber es poder". Poder, en este caso, en manos de la burguesía. Si tomamos como vía de entrada la de los fines, la diferencia salta a la vista: mientras que el conocimiento tiene como finalidad lograr la verdad, sea cual fuere lo que se entienda en cada época por verdad, la información, por el contrario, persigue el uso o utilización del conocimiento con fines de poder, control y de manipulación de las conciencias. Aquí, en la información, el conocimiento aparece sometido a fines ajenos al conocimiento.

$2^{\circ} \mathrm{El}$ conocimiento siempre ha estado incorporado en todo instrumento de creación humana, desde la más simple herramienta de la prehistoria hasta la sofisticada "revolución electrónica" actual, pasando por la revolución neolítica y la $1^{\mathrm{a}}$ y $2^{\mathrm{a}}$ revolución industrial. Dicho de otra manera, cada época ha necesitado la creación de instrumentos materiales, en base a los cuales ha podido desarrollarse esa nueva época, instrumentos que implican un mayor o distinto grado de conocimiento. Conocimiento e instrumento van a la par, este es materialización del primero, pero sin instrumentos el conocimiento no puede desarrollarse. Así, el humilde zapatero que corta la suela para hacer un par de zapatos utiliza el conocimiento o los saberes que le permiten elegir el color, la consistencia, el tamaño del cuero requerido, etc. Además, como afirma Marx (T.I cap.I de $E l$ Capital), tiene que tener previamente en la mente, la idea de lo que va a hacer, el modelo ideal del zapato que quiere fabricar, etc. Y si de estos ejemplos clásicos nos trasladamos a los agricultores y campesinos peruanos andinos, el saber que ellos poseen es inmenso y, que en muchos aspectos, no cede su lugar al saber europeo-occidental. La interrelación entre conocimiento e instrumento, o (si se quiere) la unidad entre teoría y práctica en el mundo andino, han dado lugar a las tecnologías andinas de control del agua y de la tierra, la domesticación de plantas y animales, la construcción de grandes obras monumentales. Pero si esto es muy cierto, y si esto significó la utilización del conocimiento como poder, como control y manipulación de los seres humanos, no es menos cierto que nunca, hasta ahora, se ha presentado en la historia de la humanidad, la utilización del conocimiento bajo su forma mercancía a nivel de toda la sociedad y como aspecto obligatorio o ineludible para que pueda ejercerse el proceso de producción. La universalización de este conocimiento, bajo la forma mercancía, resulta así un requisito básico sin el cual la empresa pierde productividad.

$3^{\circ}$ Quisiera señalar aquí un paralelo con la noción de conversión de la fuerza de trabajo en mercancía. La fuerza de trabajo, tan pronto se convierte en la forma mercancía, se generaliza y se vuelve obligatoria para toda actividad económica, dando lugar así a la aparición del régimen capitalista de producción o, simplemente, modo de producción capitalista. A partir de esta conversión, todo se vuelve mercancía, hasta (¿o principalmente?) el amor. De igual manera, una vez que el conocimiento se convierte en mercancía, es decir, en información, toda empresa y toda actividad económica se ve obligada a utilizar la información (o sea el conocimiento convertido en mercancía) a fin de no perder productividad. A esta etapa del imperialismo la llamamos globalización.

$4^{\circ}$ La incorporación del conocimiento-información a los procesos productivos implica la utilización cada vez mayor de los avances científicos y tecnoelectrónicos, avances que llegan a su desarrollo (por poner una fecha) en 1950, año que implica un punto de inflexión irreversible en el desarrollo del pensamiento científico y tecnológico humano. Pero lo que queremos enfatizar de esto es que no se puede concluir que los cambios tecno-electrónicos sean los responsables de los cambios sociales, específicamente de la etapa de la globalización. Es verdad que todo avance social requiere nuevos instrumentos y nueva tecnología. Así, repetimos, la revolución neolítica requirió un avance extraordinario en los conocimientos para poder tallar las piedras, tallado en el que se asienta, según Childe (1958), la agricultura y ganadería. Igualmente, la Revolución Industrial, afirma Castells (1994), es impensable sin la máquina de vapor, pero de allí no se puede llegar a la conclusión que el tallado de las piedras dio lugar a la aparición de las clases sociales ni que la máquina de vapor sea la causante de la $1^{\mathrm{a}}$ Revolución industrial(1994).

$5^{\circ}$ El pensamiento tecnicista tiene el convencimiento que la ciencia y la tecnología por sí solas son el motor de la historia, de tal manera que, según este criterio, bastaría desarrollar la ciencia y la tecnología para obtener los cambios sociales. A este modo de pensar, respondemos que es verdad que los adelantos científicos tienen una gran influencia en las condiciones materiales de vida y en la configuración de las relaciones sociales; aún más, la conversión del conocimiento en información o mercancía solo se hace posible debido a los adelantos de la cibernética 
(Wiener: 1948), de la informática (Alan Turing, 1949; Shannon y Weaver, 1949) y de la teoría general de los sistemas (Bertalanffy, 1957, 1975), pero de allí no se puede sostener un tecnicismo que desconozca el papel de la historia y de las contradicciones sociales en la generación de la ciencia y la tecnología.

$6^{\circ}$ Se pueden distinguir dos clases de factores que dieron lugar a los adelantos micro-electrónicos y telemáticos contemporáneos. Primero, las necesidades bélicas provenientes de la II Guerra Mundial (Blauberg, 1979) como son las famosas bombas V-2 alemanas, el cañón antiaéreo, la disposición del espacio en los aviones bombarderos (Bánathy, 1975), los misiles actuales y la necesidad de comunicación entre los ejércitos en conflicto. Y, en segundo lugar, la necesidad de superar la crisis y la recesión de los países centrales, lo que se expresa, como se ha señalado, en el acelerado descenso de la tasa de ganancia de las grandes empresas capitalistas. Son estos factores socio-históricos y no los puramente científicos o técnicos, los que han obrado para la concepción y desarrollo de la informática como aplicación de la información a los circuitos electrónicos, la teoría general de los sistemas de von Bertalanffy, y la idea de sistema y más concretamente la idea de sistema sistémico, es decir, el nuevo funcionalismo. Factores que, siendo producto de las urgencias sociales, sirvieron para la creación de las redes de información. Son las políticas sociales las que urgen el desarrollo científico-tecnológico para apropiarse de dichos conocimientos científicos y ponerlos a su servicio. Por estas razones, la presente no es de ninguna manera una "sociedad del conocimiento", pero la fundamentación de esto no la vamos a tratar aquí debido a diversas razones.

\section{CONCLUSIONES}

La creación de nuevos conocimientos y nuevos instrumentos se implican mutuamente en un solo proceso histórico.

Tan pronto aparece la diferenciación social, aparece también el conocimiento como información, es decir, como instrumento de poder y manipulación. En este sentido, la utilización del conocimiento ha acompañado a todo desarrollo de las civilizaciones; $\mathrm{y}$, solo en función de esa utilización, el conocimiento puede ser comprendido. Así, el conocimientomercancía ha aparecido desde mucho antes en la historia humana, pero no como una forma universal, sino, como dice Marx respecto de la fuerza de trabajo-mercancía, como "forma antediluviana", no como forma general de toda actividad económica en la sociedad.

Transcribo, como tercera conclusión, lo que escribí en mi libro La Utopía y la Vida, ya citado, Cap. 4: Hacia otra razón constructivista, p.110: "Vivimos, como lo afirma Castells (1994, 1998), una época de transición caracterizada por el tránsito hacia una sociedad informacional, la misma que se presenta como consecuencia 'del impacto combinado de una revolución tecnológica basada en tecnologías de información/comunicación, la formación de una economía global y un proceso de cambio cultural' (Castells, 1994: 15). El mismo Castells se encarga de disuadir cualquier intento de situar la revolución tecnológica en marcha en la base del cambio histórico. Por el contrario, es la sociedad y más concretamente, su actual crisis mundial de competitividad que sacude todo el sistema, lo que impulsa los cambios tecnológicos. Esto, por supuesto, no quiere decir no 'reconocer el extraordinario cambio social representado por las nuevas tecnologías' (ibid., 24). Se trata entonces del 'surgimiento de una nueva estructura social (...) asociada al surgimiento de un nuevo modo de desarrollo (del capitalismo, JVM), el informacionalismo, definido históricamente por la reestructuración del modo capitalista de producción hacia finales del siglo XX' (Castells, 1998: 40) (Negritas de JVM)" (Mendo, 2006).

El desarrollo de las tecnologías de información no ha dado lugar a la globalización, sino simplemente sucede que las nuevas tecnologías electrónicas de información o NTICs son consustanciales con el desarrollo de esta fase imperialista denominada globalización.

\section{REFERENCIAS}

Bánathy, B. (1975). "Educación y sistemas”, en W. Huertas y E. Casas, comps., Tecnología Educativa: Lima: Retablo de Papel.

Bertalanffy, L. (1957) General System Theory.

Bertalanffy, L. (1985). Teoría General de los Sistemas: México D. F.: Fondo de Cultura Económica.

Blauberg, I. (1979). Sistematicidad e integridad. Ciencias Sociales, 69-84.

Boron, A. (2002). Imperio \& imperialismo (Una lectura crítica de Michel Hardt y Antonio Negri). Colombia. 
Castells, M. (1994). Nuevas perspectivas críticas de la educación. Barcelona: Paidós.

Castells, M. (1998). La sociedad Red (Vol.1). Madrid: Alianza.

Childe, V. (1958). Los orígenes de la civilización. México: FCE.

Drucker, P. (1994). La sociedad postcapitalista. Madrid: Norma.

Lenin, V. (s/f). Imperialismo, la última etapa del capitalismo. (Varias ediciones)

Marx, K. (1956). El Capital. México D.F.: FCE.
Mendo, J. (2006). Entre la Utopía y la Vida. Lima: Fondo Editorial del Pedagógico San Marcos.

Negri, A. (2001). Entrevista por el diario La Jornada, julio 2001.

Shannon, C. y Warren, W. (1949). Mathematical Theory of Communication. Urbana: Universidad de Illinois.

Wiener, N. (1948). Cybernetics. Or control and communication in the animal and the machine. Cambridge, Mass: M.I.T. Press. 